\title{
Novice Instructional Designers' Attitudes towards the Best Possible Self Activity and the Correlation with Personality and Subjective Well-Being
}

\author{
Suzhen Duan ${ }^{1}$ (D) $\cdot$ Sunnie Watson ${ }^{2} \cdot$ Timothy Newby $^{3}$ \\ Accepted: 5 August 2021 / Published online: 6 September 2021 \\ (C) Association for Educational Communications \& Technology 2021
}

\begin{abstract}
The effectiveness of positive psychology interventions relies heavily on participants' buy-in and personality traits. The Best Possible Self (BPS) intervention asks participants to envision their ideal future, supposing that everything goes smoothly. The BPS shows salient effects in improving subjective well-being in laboratory settings. In this study, the BPS was integrated into a real-world graduate-level online course as a series of assignments. A convergent mixed method was used to explore the participants' attitudes towards the BPS and the relationship between their personality and subjective well-being. A total of 86 students registered in both the summer and spring semesters of 2020 participated in this study. Pearson correlation results show significant correlations among attitudes, subjective wellbeing and gains and openness to experience. The results from open-ended questions confirmed participants' positive attitudes towards the BPS. This study contributes to the practical application of BPS in real-world, online, higher education courses.
\end{abstract}

Keywords Attitudes $\cdot$ Best possible self intervention $\cdot$ Instructional designer $\cdot$ Openness to experience $\cdot$ Subjective well-being

\section{Introduction}

The Best Possible Self (BPS) intervention guides participants to imagine and write about their best possible selves in an

Suzhen Duan

duan63@purdue.edu

Sunnie Watson

sunnieleewatson@purdue.edu

Timothy Newby

newby@purdue.edu

1 Learning Design and Technology, Curriculum and Instruction in the College of Education, Purdue University, BRNG 3167, Steven C. Beering Hall of Liberal Arts and Education100 N. University Street, West Lafayette, IN 47907-2098, USA

2 Learning Design and Technology, Curriculum and Instruction in the College of Education, Purdue University, BRNGcaptured/presented correctly." $\rightarrow$ 3126, Steven C. Beering Hall of Liberal Arts and Education100 N. University Street, West Lafayette, IN 47907-2098, USA

3 Learning Design and Technology, Curriculum and Instruction in the College of Education, Purdue University, BRNG 3138, Steven C. Beering Hall of Liberal Arts and Education 100 N. University Street, West Lafayette, IN 47907-2098, USA ideal future (King, 2001). It is a widely used positive psychology interventions that effectively increases participants' life satisfaction, optimism, positive affect and well-being in the laboratory setting (Carrillo et al., 2019; Loveday et al., 2018). BPS has the potential to be integrated as an activity into real-world curricula because it is a short and straightforward writing activity that does not require instructors to have professional psychology knowledge to administer; it also has the flexibility to be delivered either online or face-to-face (Carrillo et al., 2019). Because it is future-oriented, the beginning of a curricular program is an excellent time to ask participants to write about their best possible selves and the steps they might take to reach their goals, since doing so can result in increased subjective well-being, including life satisfaction and positive affect and help to clarify professional goals (Layous et al., 2013).

However, little is known about how to best implement BPS in real-world settings, including in higher education courses. Many factors can influence the effectiveness of BPS and the outcomes obtained by participants. These include environmental factors and the way the activity is conducted, as well as participants' motivation, beliefs and attitudes, personalities, knowledge and awareness about the BPS (Lyubomirsky \& Layous, 2013; Sheldon \& Lyubomirsky, 2019) and their 
openness to experience (Lyubomirsky et al., 2011). Among all factors, participants' intentional buy-in, or positive attitudes about the BPS, may be most critical to its effectiveness (Sheldon \& Lyubomirsky, 2019).

In this study, we integrated the BPS into an eight-week online course as a learning activity in a master's degree program in instructional design. The participants are all novice instructional designers. Because BPS was a new activity in this course, we were especially interested in the openness to experience trait since it may influence the novice instructional designers' acceptance of and openness to the BPS intervention. We also examined the extent to which the participants' openness to experience related to their attitudes towards BPS, as well subjective well-being and changes to it.

A convergent mixed method was used to collect both quantitative and qualitative data through surveys with open-ended questions. Quantitative data includes the participants' openness to experience with six facets (intellectual efficiency, ingenuity, curiosity, aesthetics, tolerance and depth, Woo et al., 2014), attitudinal learning results towards the BPS, including four dimensions (CL: Cognitive Learning; AL: Affective Learning; BL: Behavioral Learning; and SL: Social Learning, Watson et al., 2018) and pre-and post-subjective well-being with life satisfaction and positive affect. The purpose of this study is to examine the correlation between attitudes, openness to experience and subjective wellbeing and its change from pre to post. The qualitative data from open-ended questions sheds additional light on novice instructional designers' attitudes towards the BPS. This study contributes to understanding how to implement BPS in realworld graduate-level online courses.

\section{Literature Review}

\section{Effects of the Best Possible Self (BPS)}

The BPS is a future-oriented activity whose delivery methods are highly flexible. It can be delivered either online or inperson; students, adults and behavioral health patients can all participate; and the length and number of sessions are variable (Carrillo et al., 2019; Loveday et al., 2018). In laboratory settings, research findings indicate that BPS is effective in improving subjective well-being, including increasing life satisfaction and positive affect and decreasing negative affect (Manthey et al., 2016; Boehm et al., 2011; Sheldon \& Lyubomirsky, 2006; Peters et al., 2010; Peters et al., 2016). In Carrillo et al.'s (2019) meta-analysis, among 29 studies, 23 measured positive affect and six measured life satisfaction and the results showed that BPS effectively increased positive affect, well-being and optimism compared with controls. BPS is more effective at increasing positive affect than decreasing negative affect. In another systematic review of 30 studies,
15 measured positive affect and 11 measured life satisfaction and the results also showed that BPS is an effective intervention to increase positive affect, well-being and optimism (Loveday et al., 2018). This evidence indicates that BPS is effective in increasing subjective well-being in laboratory settings. Its flexibility of length and delivery methods and its applicability to people of different ages and life stages, make it an attractive intervention to be integrated into curricula to benefit various students, such as the novice instructional designers in this study.

\section{Benefits of Applying BPS in a Real-World Course}

Seligman et al. (2009) claimed that more well-being aligns with better learning and called for applying positive psychology interventions into classroom settings. According to Fredrickson's (2001) broaden-and-build theory, "positive emotions are vehicles for individual growth and social connection: By building people's personal and social resources, positive emotions transform people for the better, giving them better lives in the future" ( $\mathrm{p} 224)$. It is critical for instructors to optimize learners' emotional states (Park, 2004) and integrating positive psychology interventions such as BPS into teaching might be an effective way to increase learners' well-being and, consequently, to benefit their learning.

Instructional designers often make decisions or give suggestions throughout the course design process about what methods or activities will be used (Hoard et al., 2019). Beyond the usual benefits for normal participants, these participants are novice instructional designers whose introduction to and attitudes about BPS could influence their decisions about including the intervention in their own future design projects. Moreover, as emerging professionals, they may have valuable insights about its application and suggestions for improvement.

\section{Factors Influencing BPS's Effectiveness}

Real-world settings have more complexity and uncontrolled factors than laboratory settings. What works in laboratory settings might not work as well or as expected in real-world settings. Three main factors potentially influencing the effectiveness of positive psychology interventions include genetic factors $(50 \%)$, circumstantial factors $(10 \%)$ and volitional or intentional activity factors (40\%), the latter of which comprises participants' knowledge, awareness and intentional buy-in (Sheldon \& Lyubomirsky, 2019). Therefore, in order to understand how to best implement BPS in the classroom, it is necessary to examine participants' attitudes towards BPS and the extent of their intentional buy-in and how these factors correlate to their subjective well-being and its change after completing the activities. 


\section{Attitudes towards BPS}

According to Watson et al. (2018), "[attitude] inherently entails an evaluation, whether positive or negative and varies according to individuals, influencing their

behavior, beliefs and feelings (affect) regarding the subject of the attitude" (p.1602). The Attitudinal Learning Inventory (ALI) is a scale designed to measure participants' attitudes towards general topics that can be adapted to any specific activity (Watson et al., 2018). In this study, we adapted it to measure participants' attitudes towards BPS in four aspects: Cognitive Learning (CL), which refers to the extent to which the learners gained information or knowledge, Affective Learning (AL), which refers to the learners' feelings or emotions, Behavioral Learning (BL), which refers to what extent to which the learners will take action as a result and Social Learning (SL), which refers to the extent to which the learners will share with or try to influence others.

In Sheldon and Lyubomirsky's (2019) study, the participants whose well-being improved the most were the ones with better attitudes towards the BPS; in contrast, the participants whose improvement to well-being was minimal had fewer positive attitudes to the BPS. Following Sheldon and Lyubomirsky (2019), in this study, we hypothesize that participants' attitudes towards BPS will correlate to their improvement in well-being. We explore participants' attitudes towards BPS and their suggestions about its implementation by analyzing qualitative data.

\section{Openness to Experience}

Openness to experience is a major dimension of personality; it highlights flexibility and reception to all experiential possibilities, which means that people with higher levels of openness to experience tend to "not only see more possibilities but also engage with them" (Christensen, 2020, p.1) and they "are more willing to try new activities and are more open to novel and unconventional ideas" (Metin-Orta \& Metin-Camgöz, 2020, p.534). Studies confirm that openness to experience is positively correlated with attitudes towards novel and unconventional ideas (e.g., counseling, Bathje et al., 2014; gay men and lesbians, Metin-Orta \& Metin-Camgöz, 2020). Because BPS is a new activity when it is integrated into general graduate classes, we hypothesize a potential correlation between openness to experience and attitudes toward BPS, meaning that participants with greater values of openness to experience will have more positive attitudes towards BPS and will in turn gain more subjective well-being improvement from the BPS.

Studies indicate a significant correlation between openness to experience and subjective well-being, including the dimensions of life satisfaction and positive affect (DeNeve \& Copper, 1998; González Gutiérrez et al., 2005). However, different studies define openness to experience in different ways (DeNeve \& Copper, 1998) and there is not a consensus about what constitutes openness to experience. Christensen et al. (2019) compared four openness to experience inventories. The results showed that Woo et al.'s (2014) openness to experience inventory was the most comprehensive. Woo et al.'s (2014) study identified six facets of openness to experience: intellectual efficiency or "efficiency in processing novel intellectual information"; ingenuity, or "preparedness to create new intellectual knowledge"; curiosity, or "attraction to novel intellectual ideas"; aesthetics, or "the appreciation of various forms of art such as paintings, classical music, buildings and landscapes"; tolerance, or "interest in learning about different cultures, preference to immerse self in new customs and traditions when traveling"; and depth, or the "desire to gain insights into oneself and the world, to self-improve and to self-actualize" (Christensen et al., 2019, p. 575). This study will explore the correlation between these six facets of openness to experience with subjective wellbeing (life satisfaction and positive affect) and each aspect of attitudes towards BPS (ALI: CL, AL, BL and SL).

\section{Research Questions}

This study aims to explore novice instructional designers' attitudes towards BPS, examine their subjective well-being changes from before to after the BPS and analyze the correlation between their subjective well-being, attitudes and openness to experience. The research questions are:

1. Is there a significant change in subjective well-being from before the BPS intervention to after it?

2. What are participants' attitudes towards BPS, as measured by the ALI and open-ended questions?

3. What is the relationship between their attitudes (ALI: four aspects) and subjective well-being (gains)?

4. What is the relationship between openness to experience (six facets), subjective well-being (gains) and attitudes (ALI: four aspects)?

\section{Methods}

\section{Participants}

Participants were graduate students who enrolled in a core foundational course in an online master's degree program majoring in learning design and technology at a Midwest University. They are also novice instructional designers because: 1) Most of them have instructional design related working experience even though they might not be formally trained before they enrolled in this program; 2) They are trained to be instructional designers in this program; 3) Most of them aim to get a position in instructional design after graduation from this program. The course is an eight-week online course named 
Foundations of learning design and technology: An introduction to the field. A total of 86 participants in both summer and fall semesters participated in this study and 77 (90\%) finished all three parts. Twenty were males $(26 \%)$ and 57 were females $(74 \%)$. The mean age was 34 years $(\mathrm{SD}=8.7)$, ranging from 21 to 61 . Sixty-two $(80.5 \%)$ identified as White, six $(7.8 \%)$ as Black or African, five $(5.7 \%)$ as Asian, three $(3.9 \%)$ as Hispanic or Latino and $1(1.3 \%)$ as Other.

\section{BPS Activity Design}

The activities and instructions for the BPS in this study were adapted from Peters et al. (2010) and Layous et al. (2013). The participants were asked to read the instructions (Fig. 1), think about their best possible selves for two minutes and then write for ten minutes (Fig. 2). Participants were also asked to write for five minutes about the goal(s) that would help them to achieve their best possible selves (Fig. 2). This BPS intervention was designed intentionally with the following considerations in mind: First, it intended to build relevance between the BPS intervention and the participants by asking them to think and write about their best possible selves as instructional designers. This is because relevance is essential for students' motivation (Keller, 1987) and students in this program are either current or hopeful instructional designers. Second, participants in one study who read a testimonial extolling the effects of the BPS gained more well-being improvement than those who did not (Layous et al., 2013). For this reason, persuasive quotes were added to our instructions from both an academic researcher and a fictional student.

\section{Instruments}

\section{Satisfaction with Life Scale (SWLS)}

SWLS was designed to measure satisfaction with life, one component of subjective well-being (Diener et al., 1985). It is a short scale including only five items in a 7-point Likert style (e.g., "In most ways my life is close to my ideal." $1=$ strongly disagree, $7=$ strongly agree; $\alpha=0.87$ ). The total scores of SWLS range from 5 to 35 , and higher scores align with higher satisfaction with life.

\section{Positive Affect (PA)}

PA was chosen from the Positive and Negative Affect Schedule (PANAS; Watson et al., 1988), which includes two 10-item scales to measure positive and negative affect independently. PA is a 5-point Likert style scale with a possible range of scores from 10 to 50 and had high reliability (PA, $\alpha=0.89$; Crawford \& Henry, 2004). The participants were asked to rate the extent of their general feelings on average (e.g., "excited," 1 = Very slightly or not at all, $5=$ Extremely). Higher PA scores align with higher positive feelings.

Fig. 1 Instruction with quotes

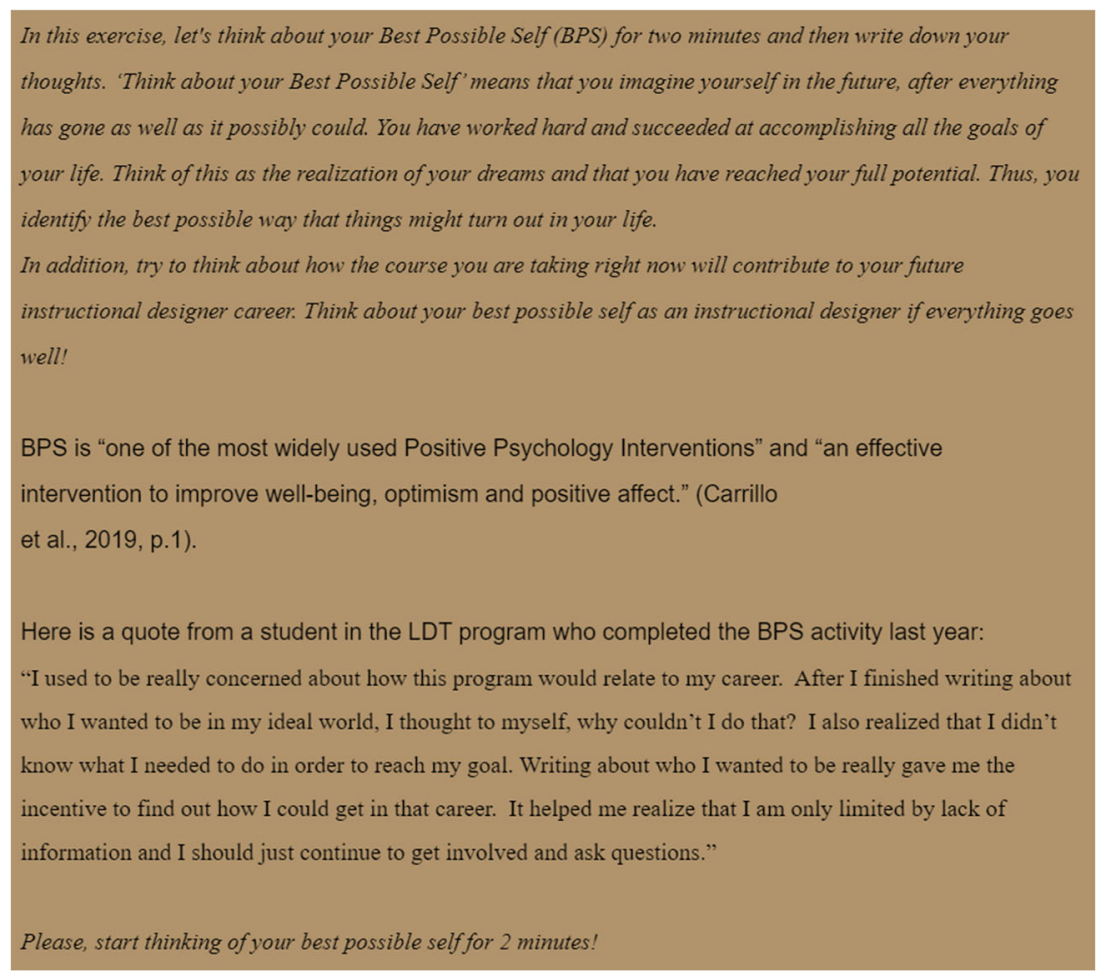


Fig. 2 Instruction of writing

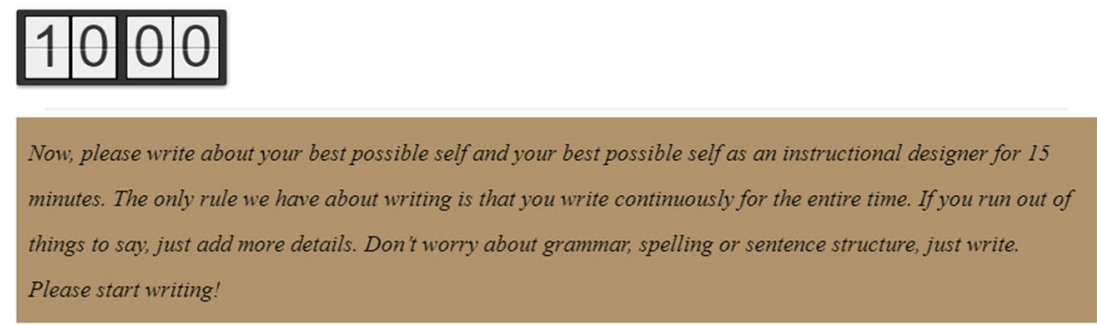

0,5100

Now, write down a goal (or goals) you might want to attain that will help you
achieve your best possible self and your best possible self as an instructional
designer like you just described. Sometimes long-term goals seem overwhelming
or out of your reach. But every journey begins with just a single step. Think about
taking baby steps towards your long-term goal (or goals). A baby step could be as
simple as proactively seeking information you need or talking to someone who
may be able to guide you. Defining the next baby step is a great way to get going
with the journey without worrying too much about the length of the road.

\section{Attitudinal Learning Inventory (ALI)}

ALI includes four aspects in a 5-point Likert style scale ( 1 = strongly disagree, $5=$ strongly agree $)$ : Cognitive Learning (CL, four items, e.g., "The activity provided me with new information"), Affective Learning (AL, three items, e.g., "I feel excitement about the activity"), Behavioral Learning (BL, four items, e.g., "I do things differently as a result of this activity") and Social Learning (SL, four items, e.g., "I educate others about this activity"). The average score for each aspect represents the degree to which participants perceived their attitudes as positive and the closer the average score is to 5 , the better the attitudes towards this activity. The reliability of ALI's four aspects is excellent, with Cronbach's alpha ranging from 0.79 to 0.93 (Watson et al., 2018).

\section{Openness to Experience}

Woo et al. (2014) identified 6 facets of openness to experience: intellectual efficiency ( $\alpha=0.83)$, ingenuity $(\alpha=0.82)$, curiosity $(\alpha=0.77)$, aesthetics $(\alpha=0.84)$, tolerance $(\alpha=$ $0.69)$ and depth $(\alpha=0.77)$; and developed a 54 scaled items in a 5-point Likert style $(1=$ strongly disagree, $5=$ strongly agree) to measure openness to experience. We used an abbreviated version of the instruments provided to us by the authors consisting of 24 items, including four for each of the following facets: intellectual efficiency (e.g., "I am very quick at processing information."), ingenuity (e.g., "I like coming up with imaginative plans."), curiosity (e.g., "I love to do experiments and see the results."), aesthetics (e.g., "I enjoy art exhibitions."), tolerance (e.g., "I enjoy (racial) diversity in the community.") and depth (e.g., "I am always interested in learning more about philosophy").

\section{Procedure}

A convergent mixed method was used in this study. Both quantitative and qualitative data were collected simultaneously through surveys with both scaled and openended questions. During the first week of this 8-week online course, a pre-test was conducted to collect prePA, pre-SWLS, openness to experience and demographic information (gender, age, ethnicity). The BPS intervention was conducted in the seventh week. The post-test was conducted in the eighth and final week of the course to collect post-PA, post SWLS and ALI. All three parts were embedded into the course as assignments in both Summer and Fall semesters. Students were required to complete all three parts to earn 10 points (6\% of the total 155 points). A total of 77 participants completed all three parts.

After the summer semester, one pilot interview was conducted to explore the participants' attitudes towards the BPS intervention. During the summer semester, we found that qualitative data helped to clarify our understanding of the participants' attitudes and thoughts. Therefore, three sets of open-ended questions were added to the post test in the fall semester. A total of 42 participants submitted their written responses to the open-ended questions offered during the Fall semester in the post test survey.

\section{Analytic Design}

A paired T-test was used to analyze the change in subjective well-being (SWLS and PA) from pre to post. Pearson 
correlation was used to analyze the correlation between attitudes towards the BPS, openness to experience, subjective well-being (SWLS and PA) and change. Both quantitative and qualitative data were analyzed to explore the participants' attitudes towards the BPS intervention.

Conventional content analysis was used to analyze the qualitative data (Hsieh \& Shannon, 2005). Because the first set of questions are about participants' attitudes towards BPS, a deductive coding process was used to code the responses by following the attitudinal learning inventory (AL, CL, BL, SL). For the second and third set of questions, since we did not have codes before reading the responses, we used an inductive coding process:

1. The responses to open-ended questions were imported into NVivo.

2. The first coder read all the responses several times to get familiar with the data.

3. Themes were identified and codes were created for each question.

4. Responses under each code were checked several times to make sure they were as accurate as possible.

5. Notes and memos were added during the process.

After the first coder completed all the coding, the codes were sent to a second coder to review the results. After the second coder gave feedback based on the first coder's coding, they discussed the differences and revised the codes iteratively until they achieved 99\% agreement (Miles \& Huberman, 1994).

\section{Results}

\section{Subjective Well-Being Change}

The descriptive data are listed in Table 1. A paired T-test was conducted to compare the pre and post SWLS and PA to measure their change from before to after the BPS. The results show no significant difference between pre and post-test scores of SWLS $(\mathrm{t}(76)=0.191, p=.849)$ and a statistically significant drop of PA $(\mathrm{t}(76)=2.725, p=.008)$, which means that the participants' satisfaction with life did not improve in a statistically significant way. In fact, their positive affect dropped significantly after the BPS intervention.

\section{Attitudes towards BPS}

In terms of participants' attitudes towards BPS, Fig. 3 shows the mean scores of ALI in Table 1. Figure 3 shows that AL is the highest, $\mathrm{CL}$ is the second highest, $\mathrm{BL}$ is the third highest and SL is the lowest, which means the participants liked the BPS intervention and thought they learned from this activity.
The results show that this intervention slightly influenced their behavior and that they probably will not share this invention with others after completing this BPS activity.

Besides the quantitative data, we analyzed three sets of open-ended questions. A total of 42 participants submitted responses. Because some did not answer all the sub-questions, the total number of responses in some categories may be less than 42. In the following section, we report the results for each set of open-ended questions.

Open-Ended Question 1 Here, you can tell us more about your feelings about this BPS learning activity; what do you learn from this activity? In what ways may it influence you?

First, we coded the responses by following ALI (AL: feelings about BPS; CL: learning from this activity; BL: influence on you. SL: sharing with others). Figure 4 shows the number of responses in each category. Most participants $(36,86 \%)$ indicated their feelings about this BPS. Nine participants (21\%) talked about what they learned from BPS and how BPS would influence their behaviors. Only two (5\%) participants said they would share this activity with others. Out of the 36 responses about their feelings to BPS, 26 (72\%) show very positive feelings, six (17\%) show neutral feelings and four (11) show negative feelings. Here are three examples of positive responses:

\begin{abstract}
"I think this was a great self-reflection and emotions check in on life. I found it very beneficial to pause and think about goals, emotions, and plans for life, both professionally and personally. I will strive to continue to routinely check in with myself as I move forward into this LDT program."
\end{abstract}

"It's nice to stop the rush, rush, rush of everyday to consider things bigger than the immediate responsibilities. Just like a vision board, writing these exercises reminded me where I want to go."

"I learned about some of my inner feelings that would not typically recognize. It helped make these apparent to me and this helped me become more aware of the things that make me happy. It also helped me think about what I want out of life and it means for me to be successful. This influences me in my daily life because I am thinking about this and trying to do more things that will make me happy and successful."

Open-Ended Question 2 Here, you can tell us a little bit more about the situations in which you will recall the content that you wrote in this activity and why. 
Table 1 The mean and standard deviation of all the variables

\begin{tabular}{|c|c|c|c|c|c|c|c|}
\hline \multirow[b]{2}{*}{ Variables } & \multirow[t]{2}{*}{ Time } & \multicolumn{2}{|c|}{ Pre $(n=77)$} & \multicolumn{2}{|c|}{ Post $(n=77)$} & \multicolumn{2}{|c|}{ Difference from post to pre } \\
\hline & & $M$ & $S D$ & $M$ & $S D$ & $M$ & $S D$ \\
\hline \multirow[t]{2}{*}{ Well-being } & SWLS & 25.429 & 5.825 & 25.506 & 6.116 & 0.078 & 3.572 \\
\hline & PA & 37.753 & 5.525 & 36.390 & 6.829 & -1.364 & 4.392 \\
\hline \multirow[t]{4}{*}{ ALI } & CL & & & 3.192 & 1.009 & & \\
\hline & $\mathrm{AL}$ & & & 3.264 & 0.909 & & \\
\hline & $\mathrm{BL}$ & & & 2.968 & 0.878 & & \\
\hline & SL & & & 2.481 & 0.911 & & \\
\hline \multirow[t]{6}{*}{ Openness to experience } & IE. & 3.672 & 0.775 & & & & \\
\hline & ingenuity & 4.133 & 0.720 & & & & \\
\hline & curiosity & 4.231 & 0.496 & & & & \\
\hline & aesthetics & 3.971 & 0.775 & & & & \\
\hline & tolerance & 4.672 & 0.420 & & & & \\
\hline & depth & 3.776 & 0.608 & & & & \\
\hline
\end{tabular}

$\mathrm{IE}=$ Intellectual efficiency
Among all the 42 responses, 31 (74\%) participants indicated that they would remember and think about BPS in the future, six (14\%) participants were not sure and five (12\%) participants did not believe they would think about their BPS in the future (Fig. 5). We analyzed the 31 responses and identified four themes:

- Future-oriented decision-making points: $16(52 \%)$ participants thought they would recall BPS during key points in their future, such as job-finding (when they graduate and find their first jobs), job transition (when they consider changing jobs), annual planning, or self-reflection (when they reflect on themselves and consider the potential directions). Most participants in this category also talked about goals, but they focused on BPS's function in guiding their long-term directions. The following are three examples:

"Perhaps in making future decisions about my professional path I will reflect upon my stated goals in this activity to inform those decisions. For example in choosing electives in this program, in deciding how to advance my current role, and in applying for and accepting future positions. I suppose I would be reflecting on if my actions aligned with how I described my BPS in this activity and were furthering me towards that version of myself."

"I wrote content pertaining to how I will work towards setting goals and objectives to help accomplish my
Fig. 3 Attitudinal mean score towards BPS

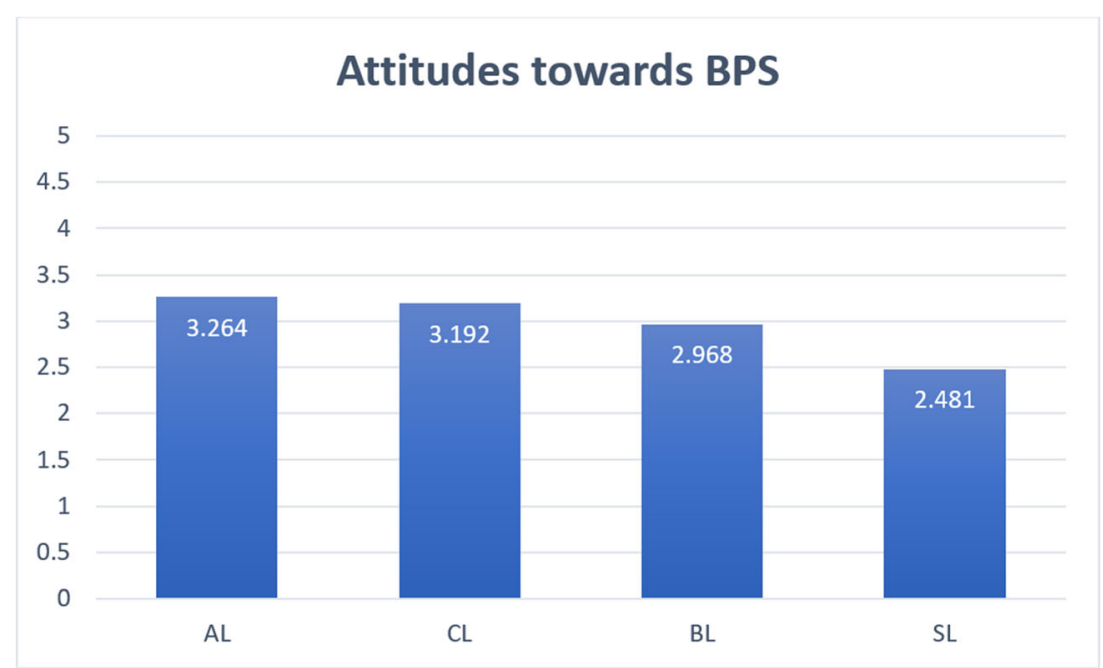




\section{Attitudinal Responses towards BPS}

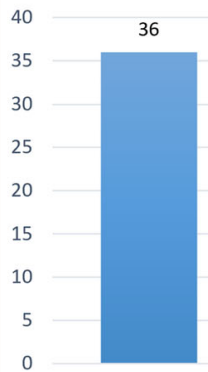

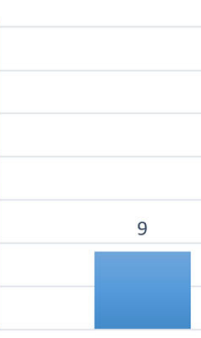

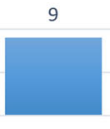

Affective Learning (AL)

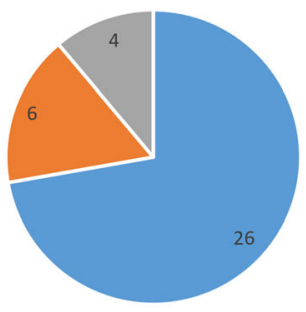

- Positive | Neutral - Negative

Fig. 4 Attitudinal responses towards BPS

plans and desires which will allow me to live the best possible life I can possibly lead. This will enhance my outlook and viewpoint on activities and jobs in day to day life."

"I hope to be able to recall the content from this activity when I get my first job in my field of study. I would like to look back and be able to say that I have moved closer to my idea of my best possible self."

- Goal setting: Seven (23\%) participants specifically talked about how BPS would help them with their goal setting or goal checking. Participants in this category also talked about how BPS would help them with future planning, as they did in the first category, but they specifically mentioned goals in their responses. Here is an example:

"When considering my goals, I can try to hold true to the responses I submitted in order to give myself the best possible life. I appreciate the aspect of reflecting on the intersection between personal and professional goals."

- Share with others: three (10\%) participants indicated that they would share this activity with others in the future. Here is an example:
"Being a leader of a team of 22, it is nice to have an awareness of myself to help me communicate better with my team. Being vulnerable and using the support of the people I work with allows me to have the strength and offer them the guidance they need to succeed with their own goals and projects. It was a great exercise in self-identifying and will help me do the same for my team."

- Without a specific timepoint: Five (16\%) of the participants took a positive view of BPS. They indicated they would remember BPS but did not specifically talk about the situations during which they might recall BPS in their future. Here is an example:

"I think that self reflection is often need and makes you think about who you are as a person and how you can always be improving to make the best possible person you can be."

Open-Ended Question 3 As an instructional designer now or in the future, how do you think this activity could be applied in your course design? What results do you expect when you

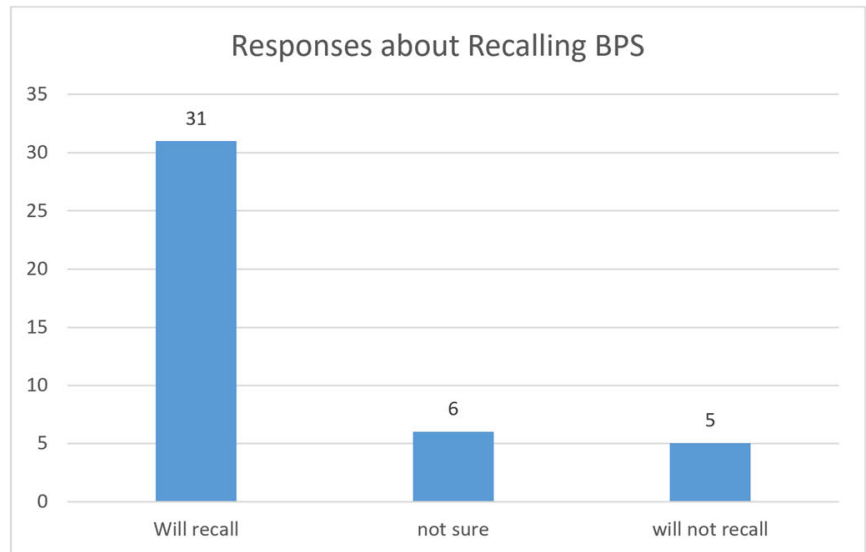

Situations of Recalling BPS

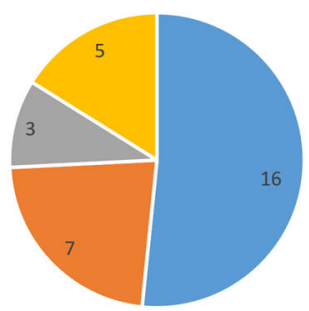

- Future-oriented decision making points $=$ Goal-setting

= Share with others

- Without a specific timepoint

Fig. 5 Responses about whether BPS will be recalled and under which circumstances 
integrate or suggest the instructors integrate this activity into a course? What changes will you make to this activity if you plan to apply it?

Figure 6 shows the results of this set of questions. Among all the 42 responses, 33 (79\%) thought BPS was a useful activity that could be integrated into their future teaching or other work. Five (12\%) participants were not sure or did not think BPS could be used in their future. Ten (24\%) participants gave suggestions about how they would revise BPS in their own application. Among the 33 participants who thought they might use BPS in their future, four themes were identified. Table 2 shows the themes, summaries of responses and example quotes.

Across all responses, the word "goals" was the most frequently used (Fig. 7).

\section{Relationship between Attitudes and Subjective Well- Being (Gains)}

In terms of the correlation between attitudes and well-being, the results show a significant correlation between the four aspects of attitudes (CL, AL, BL and SL) with pre and post well-being (SWLS, PA). The results of Pearson correlation between attitudes and well-being gains are listed in Table 3 (the difference between pre- and post-was calculated for both DiffSWLS and DiffPA). The results show that three aspects of attitudes (CL, AL, BL) were significantly correlated with satisfaction with life gains (DiffSWLS). There is no significant correlation between SL and DiffSWLS and no significant correlation between any of the four attitudinal aspects with positive affect gains (DiffPA).

\section{Relationship among Openness to Experience and Subjective Well-Being (Gains) and Attitudes}

Pearson correlation results are listed in Tables 4 and 5. Table 4 indicates that PrePA was significantly related to each of the six aspects of openness to experience and PreSWLS was significantly related to three aspects of openness to experience (Intellectual efficiency, Ingenuity and Tolerance). However, both PostSWLS and PostPA were only significantly related to two aspects of openness of experience. Furthermore, intellectual efficiency was significantly negatively related to DiffPA. Table 5 indicates that curiosity was significantly correlated to $\mathrm{AL}(r(77)$ $=.354, p=.002), \mathrm{BL}(r(77)=.280, p=.014)$ and SL $(r(77)$ $=.225, p=.050)$; and tolerance was significantly correlated to $\mathrm{AL}(r(77)=.302, p=.008)$ and $\mathrm{BL}(r(77)=.243, p=.033)$.

\section{Discussion}

In this study, we applied BPS in a graduate-level course, one of the required courses in a master's degree program. Typically, students take this course in the first semester of their two-year program. This program aims to train instructional designers and most of the participants registered in this program either have instructional design experience or hope to find a job related to instructional design after graduation. Since participants' intentional buy-in is critical for BPS's effectiveness, it is valuable to gain insight into their attitudes towards BPS using quantitative and qualitative methods. We also measured their subjective well-being and its change from before to after the BPS and the correlation between their openness to experience, attitudes and subjective well-being and the changes in these factors.

First, without a control group for comparison, it is impossible to say definitively whether or not the BPS improved well-being. Still, it is clear that there was a slight improvement in the life satisfaction metric and a significant drop in positive affect from before to after the BPS intervention. This result does not align with the findings produced in laboratory settings, which indicate that the BPS will improve participants' subjective well-being, especially life satisfaction and positive affect (Carrillo et al., 2019; Loveday et al., 2018).

This study took place during the summer (May 4-June 28) and fall (August 24-October 18) semester of 2020 during the

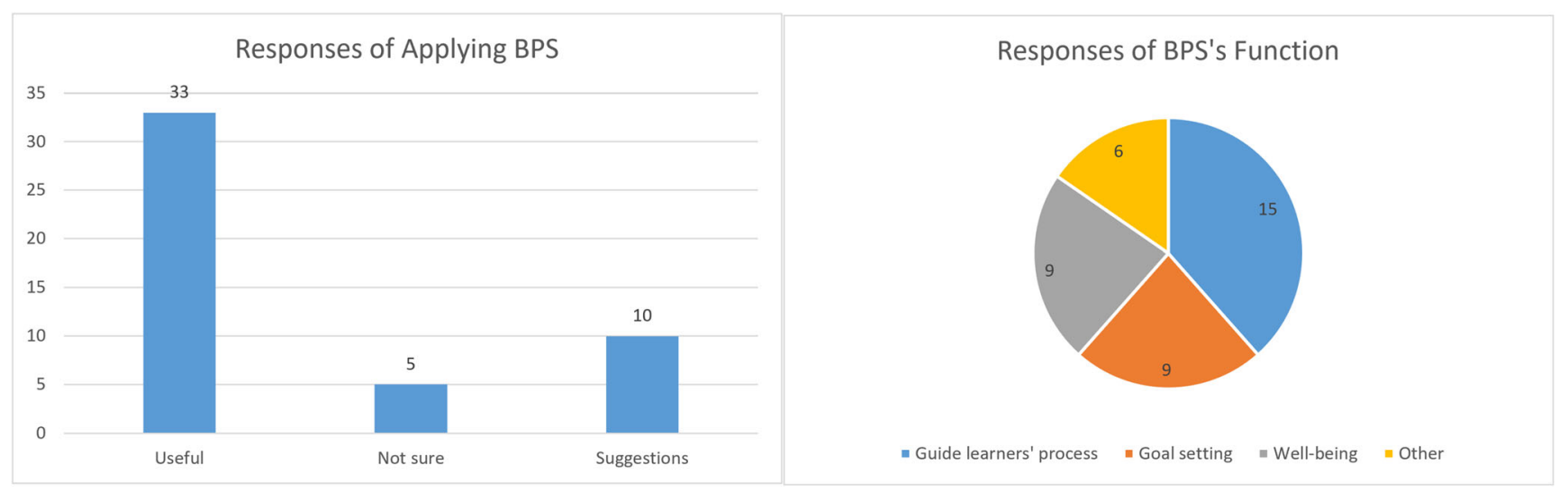

Fig. 6 Responses of applying BPS and BPS's function 
Table 2 (continued)

\begin{tabular}{cc}
\hline Themes & $\begin{array}{l}\text { Number of responses and } \\
\text { summaries }\end{array}$ \\
\hline $\begin{array}{c}\text { Goal } \\
\text { setting }\end{array}$ & $\begin{array}{l}9(27 \%) \text { participants hoped } \\
\text { to help their learners with } \\
\text { goal setting }\end{array}$
\end{tabular}

Well-being 9 (27\%) participants hoped to use BPS to improve their leaners' well-being (e.g., positive emotions, life satisfaction, motivation, engagement, positive outlook, and so on.)

Other

$6(18 \%)$ participants hoped to use BPS for other purposes (e.g., needs analysis)
Example quotes

their perspective of their best possible selves."

"This activity can be used to help learners create goals for themselves that are achievable through the course work. I would expect that learners would be able to have a positive experience and have a plan to achieve the goals they have set for themselves."

"This activity offers learners a time to reflect on their goals within and beyond a course or program of study, which of course seems beneficial as learners are prompted to visualize their BPS. I assume this practice is expected to increase learner satisfaction, self-regulation, and goal-setting skills, leading to increased learner success. I would consider connecting this practice to things that learners may already do in their lives; perhaps they already have a reflective practice or goal setting practice in their lives that achieves the same outcomes as the BPS? As an ID implementing a type of intervention like this, I would rely more heavily on growth mindset theory as I think it would provide more flexibility than the BPS activity. The underlying principles are the same, offering an intervention that cultivates a positive and adaptable view of oneself, but I think that growth mindset interventions are more directly applicable to everyday contexts."

"I believe this type of self-reflection activity could be valuable to gain understanding not only of ones self but of how others process information."
Table 2 Themes of BPS's function

\begin{tabular}{|c|c|c|}
\hline Themes & $\begin{array}{l}\text { Number of responses and } \\
\text { summaries }\end{array}$ & Example quotes \\
\hline $\begin{array}{l}\text { Guide } \\
\text { learners' } \\
\text { process }\end{array}$ & $\begin{array}{l}15(45 \%) \text { participants hoped } \\
\text { to guide their learners' } \\
\text { learning process by using } \\
\text { BPS (especially at the } \\
\text { beginning of a course or } \\
\text { program for younger } \\
\text { students such as } \\
\text { undergraduate students or } \\
\text { below) }\end{array}$ & $\begin{array}{l}\text { "I think this activity would } \\
\text { be well-suited for an aca- } \\
\text { demic environment. If I } \\
\text { work as an ID for a } \\
\text { campus, much like it has } \\
\text { been used here, I would } \\
\text { incorporate it into the } \\
\text { course material. I think } \\
\text { this could be especially } \\
\text { helpful for incoming } \\
\text { freshmen to complete as } \\
\text { part of their orientation } \\
\text { and perhaps, each year to } \\
\text { track how their perspec- } \\
\text { tive shifts and refines in } \\
\text { the course of pursuing } \\
\text { their degree. I would ex- } \\
\text { pect that students would } \\
\text { walk a way with a clear } \\
\text { sense of purpose and mo- } \\
\text { tivation for their choice in } \\
\text { pursuing their goal. One } \\
\text { thing, this activity felt } \\
\text { misplaced in my EDCI } \\
513 \text { course. It didn't feel } \\
\text { as though it was well-- } \\
\text { integrated, rather that it } \\
\text { was just a nice activity } \\
\text { tagged on to the course. I } \\
\text { would like to see this ac- } \\
\text { tivity either more fully in- } \\
\text { corporated into the course } \\
\text { or as part of orientation. } \\
\text { Maybe students could } \\
\text { create infographics around }\end{array}$ \\
\hline
\end{tabular}

COVID-19 pandemic. Kachanoff et al.'s (2020) study indicated that COVID-19 led to a significant decrease in well-being in the US. Furthermore, Zacher and Rudolph's (2020) study showed that none of 14 coping strategies aiming to raise wellbeing worked during the pandemic and their future planning strategy was negatively related to well-being. As Zacher and Rudolph (2020) explained, "the high levels of insecurity associated with the pandemic may have turned future planning into a dissatisfying experience" (p. 60). Duan et al.'s (2021) study confirmed Zacher and Rudolph's (2020) study by finding that participants in their BPS group (who were asked to write about their best possible self) gained less of an increase in well-being than participants in the control group (who were asked to write about their typical day) during the pandemic. These combined findings seem to suggest that BPS might not work as well under the conditions of a global pandemic as it does under typical conditions. 


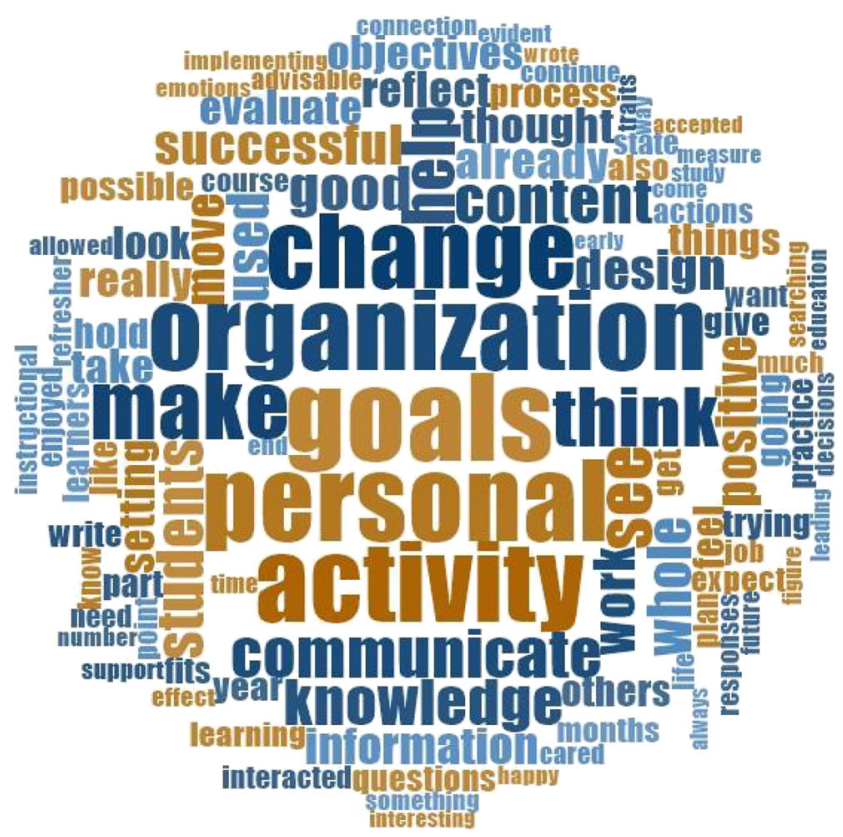

Fig. 7 Word cloud by frequency among all responses

Despite this, most participants held positive attitudes towards the BPS. Among all four aspects of ALI, the participants had higher affective and cognitive learning scores than behavioral and social learning scores, which means they liked this activity and thought they learned something new. Furthermore, results from the analysis of the open-ended questions provided some positive evidence about participants' attitudes and thoughts about the BPS. First, most participants held positive attitudes towards the BPS and said they would recall the content of their BPS in the future to help them with goal setting, goal checking and guidance for their growth. Second, most participants think the BPS could be applied in their future teaching or other work to help their learners with goal setting and goal checking, to guide students about the learning process and to promote well-being. Still, the mean scores of behavioral and social learning are below 3 points (Fig. 3), which indicated that many participants did not think that their behavior had changed because of the intervention and they did not think they would share this activity or try to influence others by applying it. Results from qualitative data align well with the quantitative data on the behavioral and social aspects, which showed lower percentage of participants who thought this intervention would influence their behavior and share with others. Considering that there was only one week between when they completed the intervention and took the post test with ALI, the short time span might not allow them to change their behavior or share with others. Further study needed to explore more on these two aspects in the future.

Nonetheless, the correlation between attitudes and wellbeing is very encouraging, since all four aspects of attitudes significantly correlated to both pre and post life satisfaction and positive affect. Except for social learning, all three of the other aspects significantly correlated to improvement in life satisfaction. These findings confirmed our hypothesis that participants with intentional buy-in (with higher attitudes scores) would have higher levels of well-being and that they would gain more well-being through BPS (Sheldon \& Lyubomirsky, 2019). While no significant correlation was found between attitudes and improvement in positive affect, the reason might be the unexpected drop in positive affect under the conditions of the global pandemic (Kachanoff et al., 2020).

The correlation between openness to experience and attitudes is also noteworthy. Participants with higher curiosity tended to have higher affective, behavioral and social learning results. Furthermore, participants with higher tolerance tended to have higher affective and behavioral learning results. Even though not all sub-aspects of openness to experience were significantly related to all sub-aspects of ALI, these findings

Table 3 Correlation between attitudes and well-being

\begin{tabular}{|c|c|c|c|c|c|c|c|c|c|c|c|c|}
\hline Variable & $M$ & $S D$ & 1 & 2 & 3 & 4 & 5 & 6 & 7 & 8 & 9 & 10 \\
\hline 1. CL & 3.19 & 1.009 & - & & & & & & & & & \\
\hline 2. AL & 3.26 & 0.909 & $.670^{* * *}$ & - & & & & & & & & \\
\hline 3. BL & 2.97 & 0.878 & $.609^{* *}$ & $.725^{* *}$ & - & & & & & & & \\
\hline 4. SL & 2.48 & 0.911 & $.437^{* *}$ & $.657^{* *}$ & $.606^{* *}$ & - & & & & & & \\
\hline 5. PreSWLS & 25.43 & 5.825 & $.266^{*}$ & $.252^{*}$ & $.286^{*}$ & $.287^{*}$ & - & & & & & \\
\hline 6. PrePA & 37.75 & 5.525 & $.320^{* *}$ & $.507^{* *}$ & $.405^{* *}$ & $.374^{* *}$ & $.523^{* *}$ & - & & & & \\
\hline 7. PostSWLS & 25.51 & 6.116 & $.430^{* *}$ & $.395^{* *}$ & $.416^{* *}$ & $.382^{* *}$ & $.822^{* * *}$ & $.497^{* *}$ & - & & & \\
\hline 8. PostPA & 36.39 & 6.829 & $.369^{* *}$ & $.519^{* *}$ & $.439^{* *}$ & $.418^{* *}$ & $.500^{* *}$ & $.767^{* *}$ & $.544^{* *}$ & - & & \\
\hline 9. DiffSWLS & .08 & 3.572 & $.303^{* *}$ & $.267^{*}$ & $.245^{*}$ & 0.186 & -0.223 & 0.000 & $.372^{* * *}$ & 0.115 & - & \\
\hline 10. DiffPA & -1.36 & 4.392 & 0.170 & 0.169 & 0.173 & 0.179 & 0.120 & -0.066 & 0.220 & $.590^{* *}$ & 0.180 & - \\
\hline
\end{tabular}

$* * . p<.001 . * . p<.005$ 
Table 4 Correlation between openness to experience and well-being

\begin{tabular}{|c|c|c|c|c|c|c|c|c|c|c|c|c|c|c|}
\hline Variable & $M$ & $S D$ & 1 & 2 & 3 & 4 & 5 & 6 & 7 & 8 & 9 & 10 & 11 & 12 \\
\hline 1. IE & 3.67 & 0.775 & - & & & & & & & & & & & \\
\hline 2. Ingenuity & 4.13 & 0.720 & $.484^{* *}$ & - & & & & & & & & & & \\
\hline 3. Curiosity & 4.23 & 0.496 & $.244^{*}$ & $.414^{* *}$ & - & & & & & & & & & \\
\hline 4. Aesthetics & 3.97 & 0.775 & 0.095 & $.318^{* *}$ & $.358^{* *}$ & - & & & & & & & & \\
\hline 5. Tolerance & 4.67 & 0.420 & 0.214 & 0.217 & $.296^{* *}$ & $.230^{*}$ & - & & & & & & & \\
\hline 6. Depth & 3.78 & 0.608 & $.235^{*}$ & $.383^{* *}$ & $.561^{* *}$ & $.538^{* * *}$ & $.282^{*}$ & - & & & & & & \\
\hline 7. PreSWLS & 25.43 & 5.825 & $.254^{*}$ & $.268^{*}$ & 0.185 & 0.114 & $.312^{* *}$ & 0.070 & - & & & & & \\
\hline 8. PrePA & 37.75 & 5.525 & $.367^{* *}$ & $.444^{* *}$ & $.444^{* *}$ & $.231^{*}$ & $.414^{* *}$ & $.345^{* *}$ & $.523^{* *}$ & - & & & & \\
\hline 9. PostSWLS & 25.51 & 6.116 & $.238^{*}$ & $.240^{*}$ & 0.081 & -0.002 & 0.174 & 0.080 & $.822^{* *}$ & $.497^{* * *}$ & - & & & \\
\hline 10. PostPA & 36.39 & 6.829 & 0.124 & 0.222 & $.287^{*}$ & 0.055 & $.351^{* *}$ & 0.196 & $.500^{* *}$ & $.767^{* * *}$ & $.544^{* *}$ & - & & \\
\hline 11. DiffSWLS & .08 & 3.572 & -0.006 & -0.026 & -0.162 & -0.189 & -0.211 & 0.023 & -0.223 & 0.000 & $.372^{* *}$ & 0.115 & - & \\
\hline 12. DiffPA & -1.36 & 4.392 & $-.269^{*}$ & -0.213 & -0.113 & -0.205 & 0.025 & -0.128 & 0.120 & -0.066 & 0.220 & $.590^{* * *}$ & 0.180 & - \\
\hline
\end{tabular}

IE $=$ Intellectual efficiency. ${ }^{* *} . p<.001 . * . p<.005$

partially confirmed our hypothesis that participants with a higher score of openness to experience would have a higher score in attitudes towards BPS (Metin-Orta \& Metin-Camgöz, 2020). More studies with larger sample sizes need to be conducted to confirm this correlation.

The correlation between all facets of openness to experience and pre positive affect is significant, while only some facets of openness to experience significantly correlated to post positive affect and pre and post life satisfaction. Furthermore, no significant correlation was found between openness to experience and life satisfaction change. These findings indicate that participants with higher openness to experience tend to have higher subjective well-being ((DeNeve \& Copper, 1998; González Gutiérrez et al., 2005)), but no direct evidence shows that they will attain additional subjective well-being gains through BPS. We also found that intellectual efficiency negatively correlated to positive affect improvement. We did not find related literature that could help explain this phenomenon, more studies are needed to explore their correlation.

\section{Limitations}

There are several limitations in this study. First, we used a one-group design without a control group to compare with, so it is difficult to say whether BPS was the cause of improved well-being. Second, we collected the post data one week after the BPS intervention. This strategy did not allow us to measure possible long-term effects. Third, our BPS intervention took place during a single session and it is possible that multiple sessions over a longer period of time might have a more significant influence on subjective well-being. Fourth, the sample size in this study is small and therefore our results are not necessarily representative of the larger graduate

Table 5 Correlation between openness to experience and attitudes

\begin{tabular}{|c|c|c|c|c|c|c|c|c|c|c|c|c|}
\hline Variable & $M$ & $S D$ & 1 & 2 & 3 & 4 & 5 & 6 & 7 & 8 & 9 & 10 \\
\hline 1. IE & 3.67 & 0.775 & - & & & & & & & & & \\
\hline 2. Ingenuity & 4.13 & 0.720 & $.484^{* *}$ & - & & & & & & & & \\
\hline 3. Curiosity & 4.23 & 0.496 & $.244^{*}$ & $.414^{* *}$ & - & & & & & & & \\
\hline 4. Aesthetics & 3.97 & 0.775 & 0.095 & $.318^{* * *}$ & $.358^{* *}$ & - & & & & & & \\
\hline 5. Tolerance & 4.67 & 0.420 & 0.214 & 0.217 & $.296^{* *}$ & $.230^{*}$ & - & & & & & \\
\hline 6. Depth & 3.78 & 0.608 & $.235^{*}$ & $.383^{* *}$ & $.561^{* *}$ & $.538^{* *}$ & $.282^{*}$ & - & & & & \\
\hline 7. CL & 25.51 & 6.116 & 0.190 & 0.116 & 0.165 & -0.103 & 0.123 & 0.110 & - & & & \\
\hline 8. AL & 36.39 & 6.829 & 0.137 & 0.214 & $.354^{* *}$ & 0.125 & $.302^{* *}$ & 0.210 & $.670^{* * *}$ & - & & \\
\hline 9. $\mathrm{BL}$ & .08 & 3.572 & 0.035 & 0.091 & $.280^{*}$ & -0.021 & $.243^{*}$ & 0.117 & $.609^{* * *}$ & $.725^{* *}$ & - & \\
\hline 10. SL & -1.36 & 4.392 & 0.195 & 0.198 & $.225^{*}$ & 0.089 & 0.127 & 0.126 & $.437^{* *}$ & $.657^{* *}$ & $.606^{* *}$ & - \\
\hline
\end{tabular}

IE $=$ Intellectual efficiency. ${ }^{* *} . p<.001 . * . p<.005$ 
student population. Finally, participants' stress related to the COVID-19 pandemic may have influenced the results.

\section{Implications}

Findings of this study indicate the following guidance for practitioners, including instructors, instructional designers, or program developers, who hope to apply the BPS in online graduate-level courses or programs:

1. The BPS's effectiveness in increasing subjective wellbeing could be influenced by the pandemic situation, such as COVID-19. It may be less suitable under highly uncertain or stressful conditions.

2. Most participants in this study hold positive attitudes towards BPS. Its implementation in this study could serve as a good application example for practitioners.

3. Participants with higher openness to experience tend to have more positive attitudes towards BPS and more positive attitudes lead to more subjective well-being and life satisfaction gains. However, higher openness to experience doesn't correlate directly to more subjective wellbeing gains. Thus, compared to openness to experience, attitudes towards BPS are a better indicator of its potential effectiveness.

4. For practitioners, trying to increase participants' positive attitudes towards BPS will likely improve its effectiveness.

5. Based on the novice instructional designers" suggestions, a number of variations to application could prove useful. For example, participants suggested that BPS might best be implemented during critical points in time, such as the beginning of a program, semester, or a year. This would allow these same students to reflect at a later point on the goals they set earlier and determine the extent to which they are meeting those goals - in other words, to reflect on how they are becoming their ideal selves.

6. Responses to the open-ended questions suggested that BPS might be more beneficial for younger students with less experience and less clarity about their future.

\section{Conclusion and Future Research}

This study enhances our understanding of participants' attitudes towards BPS. It provides insights into the correlation between participants' openness to experience, attitudes, subjective well-being and subjective well-being gains, especially at the micro-level. In our study, BPS did not increase participants' well-being. However, most participants held positive attitudes towards BPS and provided valuable insights and suggestions for future application of this intervention in the instructional design.

For future studies, there are several implications: First, a control group is essential for measuring BPS's effect on subjective well-being. Second, it is valuable to conduct studies among expert instructional designers to collect their suggestions about the application of BPS in instructional design. Third, more studies with larger sample sizes would help confirm the correlation between openness to experience, attitudes towards the BPS, subjective well-being and subjective wellbeing gains, especially in terms of their sub-aspects. Finally, it would be useful to study participants' suggestion to use BPS over a more extended period of time. Such an approach would allow researchers to check in and make adjustments during a middle phase and measure any differences at a concluding phase.

Funding No funds, grants, or other support was received.

\section{Declarations}

Ethics Approval The questionnaire and methodology for this study was approved by the Human Research Protection Program of Purdue University (Institutional Review Board number: 1502015791).

Consent Based on the approval of Institutional Review Board (IRB) at Purdue University, the consent of all the data collection surveys in this study are exempted.

Conflict of Interest The authors have no conflicts of interest to declare that are relevant to the content of this article.

\section{References}

Bathje, G. J., Kim, E., Rau, E., Bassiouny, M. A., \& Kim, T. (2014). Attitudes toward face-to-face and online counseling: Roles of selfconcealment, openness to experience, loss of face, stigma, and disclosure expectations among Korean college students. International Journal for the Advancement of Counselling, 36(4), 408-422. https://doi.org/10.1007/s10447-014-9215-2

Boehm, J. K., Lyubomirsky, S., \& Sheldon, K. M. (2011). A longitudinal experimental study comparing the effectiveness of happinessenhancing strategies in Anglo Americans and Asian Americans. Cognition and Emotion, 25(7), 1263-1272. https://doi.org/10. 1080/02699931.2010.541227

Carrillo, A., Rubio-Aparicio, M., Molinari, G., Enrique, Á., SánchezMeca, J., \& Baños, R. M. (2019). Effects of the best possible self intervention: A systematic review and meta-analysis. PLoS One, 14(9), 1-23. https://doi.org/10.1371/journal.pone.0222386

Christensen, A. P., Cotter, K. N., \& Silvia, P. J. (2019). Reopening openness to experience: A network analysis of four openness to experience inventories. Journal of Personality Assessment, 101(6), 574588. https://doi.org/10.1080/00223891.2018.1467428

Christensen, A. P. (2020). Openness to experience. In V. Glăveanu (Ed.), The Palgrave encyclopedia of the possible. Palgrave Macmillan. https://oi.org/10.1007/978-3-319-98390-5113-1 
Crawford, J. R., \& Henry, J. D. (2004). The positive and negative affect schedule (PANAS): Construct validity, measurement properties and normative data in a large non-clinical sample. British Journal of Clinical Psychology, 43(3), 245-265. https://doi.org/10.1348/ 0144665031752934

Diener, E., Emmons, R. A., Larsen, R. J., \& Griffin, S. (1985). The satisfaction with life scale. Journal of Personality Assessment, 49, 71-75. https://doi.org/10.1207/s15327752jpa4901

DeNeve, K. M., \& Copper, H. (1998). The happy personality: A metaanalysis of 137 personality traits and subjective well-being. Psychological Bulletin, 124(2), 197-229 https://www.gwern.net/ docs/iq/1998-deneve.pdf

Duan,S., Exter, M., Newby, T., \& Fa, B. (2021). No impact? Long-term effects ofapplying the best possible self intervention in a real-world undergraduateclassroom setting. International Journal of Community Well-Being. https://doi.org/10.1007/s42413-02100120-y

Fredrickson, B. L. (2001). The role of positive emotions in positive psychology: The broaden-and-build theory of positive emotions. American Psychologist, 56(3), 218-226.

González Gutiérrez, J. L., Jiménez, B. M., Hernández, E. G., \& Puente, C. P. (2005). Personality and subjective well-being: Big five correlates and demographic variables. Personality and Individual Differences, 38(7), 1561-1569. https://doi.org/10.1016/j.paid.2004.09.015

Hoard, B., Stefaniak, J., Baaki, J., \& Draper, D. (2019). The influence of multimedia development knowledge and workplace pressures on the design decisions of the instructional designer. Educational Technology Research and Development, 67(6), 1479-1505. https://doi.org/10.1007/s11423-019-09687-y

Hsieh, H.-F., \& Shannon, S. E. (2005). Three approaches to qualitative content analysis. Qualitative Health Research, 15(9), 1277-1288. https://doi.org/10.1177/1049732305276687

Kachanoff,F., Bigman, Y. E., Kapsaskis, K., \& Gray, K. (2020). Measuring realisticand symbolic threats of COVID-19 and their unique impacts on wellbeing andadherence to public health behaviors. Social Psychological and PersonalityScience, 12(5), 603-616. https://doi.org/10.1177/1948550620931634

Keller, J. M. (1987). Development and use of the ARCS model of instructional design. Journal of Instructional Development, 10(3), 2 10.

King, L. A. (2001). The health benefits of writing about life goals. Personality and Social Psychology Bulletin, 27(7), 798-807. https://doi.org/10.1177/0146167201277003

Layous, K., Nelson, S. K., \& Lyubomirsky, S. (2013). What is the optimal way to deliver a positive activity intervention? The case of writing about one's best possible selves. Journal of Happiness Studies, 14(2), 635-654. https://doi.org/10.1007/s10902-012-93462

Loveday, P. M., Lovell, G. P., \& Jones, C. M. (2018). The best possible selves intervention: A review of the literature to evaluate efficacy and guide future research. Journal of Happiness Studies, 19(2), 607-628. https://doi.org/10.1007/s10902-016-9824-z

Lyubomirsky, S., Dickerhoof, R., Boehm, J. K., \& Sheldon, K. M. (2011). Becoming happier takes both a will and a proper way: An experimental longitudinal intervention to boost well-being. Emotion, 11(2), 391-402. https://doi.org/10.1037/a0022575

Lyubomirsky, S., \& Layous, K. (2013). How do simple positive activities increase well-being? Current Directions in Psychological Science, 22(1), 57-62. https://doi.org/10.1177/0963721412469809
Manthey, L., Vehreschild, V., \& Renner, K. H. (2016). Effectiveness of two cognitive interventions promoting happiness with video-based online instructions. Journal of Happiness Studies, 17(1), 319-339. https://doi.org/10.1007/s10902-014-9596-2

Metin-Orta, I., \& Metin-Camgöz, S. (2020). Attachment style, openness to experience, and social contact as predictors of attitudes toward homosexuality. Journal of Homosexuality, 67(4), 528-553. https:// doi.org/10.1080/00918369.2018.1547562

Miles, M. B., \& Huberman, A. M. (1994). Qualitative data analysis: An expanded sourcebook. Thousand Oaks, CA: Sage.

Park,S. (2004). Building bridge between learning and positive emotion: How to applyemotional factor in instructional designing process? Association forEducational Communications and Technology, 9. http://eric.ed.gov/ERICWebPortal/recordDetail?accno=ED485056

Peters, M. L., Flink, I. K., Boersma, K., \& Linton, S. J. (2010). Manipulating optimism: Can imagining a best possible self be used to increase positive future expectancies? Journal of Positive Psychology, 5(3), 204-211. https://doi.org/10.1080/ 17439761003790963

Peters, M. L., Vieler, J. S. E., \& Lautenbacher, S. (2016). Dispositional and induced optimism lead to attentional preference for faces displaying positive emotions: An eye-tracker study. Journal of Positive Psychology, 11(3), 258-269. https://doi.org/10.1080/ 17439760.2015.1048816

Seligman, M. E. P., Ernst, R. M., Gillham, J., Reivich, K., \& Linkins, M. (2009). Positive education: Positive psychology and classroom interventions. Oxford Review of Education, 35(3), 293-311. https:// doi.org/10.1080/03054980902934563

Sheldon, K. M., \& Lyubomirsky, S. (2006). How to increase and sustain positive emotion: The effects of expressing gratitude and visualizing best possible selves. Journal of Positive Psychology, 1(2), 73-82. https://doi.org/10.1080/174397605005106766

Sheldon, K.M., \& Lyubomirsky, S. (2019). Revisiting the sustainable happiness modeland pie chart: Can happiness be successfully pursued? Journal of PositivePsychology, 16(2), 145-154. https://doi. org/10.1080/17439760.2019.1689421

Watson, S. L., Watson, W. R., \& Tay, L. (2018). The development and validation of the attitudinal learning inventory (ALI): A measure of attitudinal learning and instruction. Educational Technology Research and Development, 66(6), 1601-1617. https://doi.org/10. 1007/s11423-018-9625-7

Watson, D., Clark, L. A., \& Tellegen, A. (1988). Development and validation of brief measures of positive and negative affect: The PANAS scales. Journal of Personality and Social Psychology, 54, 1063-1070.

Woo, S. E., Chernyshenko, O. S., Longley, A., Zhang, Z. X., Chiu, C. Y., $\&$ Stark, S. E. (2014). Openness to experience: Its lower level structure, measurement, and cross-cultural equivalence. Journal of Personality Assessment, 96(1), 29-45. https://doi.org/10.1080/ 00223891.2013.806328

Zacher, H., \& Rudolph, C. W. (2020). Individual differences and changes in subjective wellbeing during the early stages of the COVID-19 pandemic. American Psychologist, 76(1), 50-62. https://doi.org/ 10.1037/amp0000702

Publisher's Note Springer Nature remains neutral with regard to jurisdictional claims in published maps and institutional affiliations. 